DOI: http://dx.doi.org/10.12775/ths.2016.005

\author{
Roberta P. Mocerino \\ MIUR - Ministero dell'Istruzione (Italia) \\ rpmocerino@gmail.com
}

\title{
Gesture, Interjection and Onomatopoeia in Edward Burnett Tylor's Theory of the Origin and Development of Language
}

\begin{abstract}
In this paper, I shall focus on E. B. Tylor's theory on the origin and development of language, as it is expounded in his Researches into the Early History of Mankind (1865), in Primitive Culture (1871) and in Anthropology (1881). In his first work, influenced by Charles Darwin and Max Müller, he tried to explain the emergence of human language from what he called "Gesture-Language". This line of inquiry prompted him to discuss the relation between objects and names, which in turn led him to the conclusion that primitive minds cannot separate "objects" from "ideas". This idea stands at the core of his most famous theory, that is, "Primitive Animism". Tylor's theory of "Gesture-Language" was in contrast with Müller's idea of language as the "Rubicon" that separates Men from Animals. This opposition is analysed in Primitive Culture and Anthropology, where Tylor explicitly discusses of interjectional and imitative theories.
\end{abstract}

Keywords: origin of language; gesture-language; interjection; onomatopoeia; emotional tone; natural language; Darwinian debate.

\section{The Victorian debate on language: Continuity vs. Discontinuity theories}

The power which man possesses of uttering his thoughts is one of the most essential elements of his civilization. Whether he can even think at all 
without some means of outward expression is a metaphysical question which need not be discussed here. Thus much will hardly be denied by any one, that man's power of utterance, so far exceeding any that the lower animals possess, is one of the principal causes of his immense preminence over them.

(Tylor 1870: 14)

Darwin's Origin of the Species marked the beginning of a new era in many fields of studies, not to mention the rise of new branches of biology. The thorniest aspect of his theory concerned the place of human beings in nature and their derivation from lower animals. As it is well known, in his Origin of the Species Darwin intentionally bypassed the question of the origin of human beings - which was to be the topic of his 1871 work, Descent; nonetheless, his contemporaries were quick to point out the difficulties his theory implied. The ensuing discussion influenced the British biological, philosophical, religious, psychological, anthropological, ethnographic and linguistic debate for decades to come.

For what concerns language, the problem raised by the theories of evolution may be framed as follows: if human beings, which are speaking beings, evolved from non-speaking lower animals, how are we to explain the rise of the language faculty in the Homo species? Upholders of Darwin's theory maintained, on the basis of various arguments, a continuity theory, according to which the language faculty - traditionally considered the most specific human trait - had to be interpreted as an evolution of communicative skills that were shared by lower species. The famous German philologist Max Müller, on the other hand, countered such continuity theory through the well-known "Rubicon theory", that is, the idea that there is an essential difference between animal signs and human language:

Where, then, is the difference between brute and man? What is it that man can do, and of which we find no signs, no rudiments, in the whole brute world? I answer without hesitation: the one great barrier between the brute and man is Language. Man speaks, and no brute has ever uttered a word. Language is our Rubicon, and no brute will dare to cross it. (Müller 1861: 354-5, my italics)

E. B. Tylor's work taps into this debate, though from a different perspective: for Tylor turns to the inquiry into language as part of a broader theoretical framework, namely that provided by cultural anthropology, which was then in the process of formation. 
Tylor's first steps into academic studies were marked by Quakerism and Prichardian anthropology. Not only did he receive an early Quaker education: during his crucial trip to Mexico, his mentor was Henry Christy, a fellow of the British Ethnological Society and an ethnologist and a Quaker himself. ${ }^{1}$ Prichardian anthropology, on the other hand, had been the default position within the British Academy until the foundation of the Anthropological Society, which endorsed different positions. Among Prichard's basic principles there was a belief in the fundamental unity of human kind, which was grounded on a number of evidences drawn from a range of fields: for instance, history, comparative anatomy, travel literature and compared linguistics. ${ }^{2}$

This particular bent of thought is clearly discernible in Tylor's epistemological attitude towards his subject-matter, i.e. culture. As his most famous definition has it:

Culture or Civilization, taken in its wide ethnographic sense, is that complex whole which includes knowledge, belief, art, morals, law, custom, and any other capabilities and habits acquired by man as a member of society. (Tylor 1871:1)

Tylor's definition of culture obviously includes languages and speech; but what about the language faculty (i.e. the saussurian langage)? Language is indeed a critical factor when it comes to discussing the relationship between man and society. Charles Darwin himself labelled the language faculty "half art, half instinct" (Darwin 1871: II, 390), meaning that its essence lies not in men's natural disposition to acquire a particular language nor in the variety of dialects and speeches that may be found world-wide: rather, language is half nature, half culture. In other words, from a Darwinian point of view - which Tylor always maintained along with his original Prichardian imprinting - the study of linguistic phylogeny might disclose some evidence about human evolution:

In carrying on the enquiry into the development of culture, evidence of some weight is to be gained from an examination of Language. Comparing the grammars and dictionaries of races at various grades of civilization, it appears that, in the great art of speech, the educated man at this day substantially uses the method of the savage, only expanded and improved in the working out of details. (Tylor 1871, vol. I, p. 149)

See Stocking (1968, 1973, 1987).

See Stocking (1973) and Mocerino (2015). 
Once this methodological premises are accepted, one can easily understand why barely half of Tylor's Researches deal with the problem of language, and in particular with primitive language. Language as an object of study is reduced to its basic components: for what concerns the channel, we are provided a first, rough division between forms of communication that exploit visuo-spatial skills (what Tylor called "Gesture-Language" and "PictureWriting"), and those that rely on uttering and hearing sounds ("Speech" and "Phonetic Alphabets"). At a closer look, however, a different categorisation, based on the quality of the connection between "signs" and "objects", emerges. The simplest communication systems - whether visuo-spatial or phono-acoustic - are based on symbols that display an evident connection between sign and object. The signs and the systems they form may thus be placed along a scale that marks the degree of evidence of the sign-object connection, from a minimum to a maximum degree. The scale may therefore include the following progressive steps: from a simple pointing, in which the proximity is evident even from a spatial point of view; to onomatopoeia, which exploits sound similarity; to interjection, which belongs to the realm of sensorial shift, as it requires the sound produced under the urge of an internal emotion to be decontextualised and reemployed to indicate an external class of objects or events; to highly formalised systems like symbolic logic, where the connection is so abstract that may appear as entirely lost. This is what allows Tylor to write as follows in Primitive Culture:

Comparing the grammars and dictionaries of races at various grades of civilization, it appears that, in the great art of speech, the educated man at this day substantially uses the method of the savage, only expanded and improved in the working out of details.

(Tylor 1871: I, 149)

\section{The Gesture-Language}

Tylor's Researches, however, are mostly devoted to the inquiry into GestureLanguage. Gesture language is not only one of the favourite channels of communication for children and primitive people - as it is shown by the wide use the latter make of it to accompany spoken words ${ }^{3}$; like

"To this prominent condition of gesture as a means of expression among rude tribes, and to the development of pantomime in public show and private intercourse among such peoples as the Neapolitans of our own day, the most extreme contrast may be found in England, 
spoken language, gesture language is also liable to be entirely codified, as it happens in deaf-mute communities where it is used as a mother tongue. These features enable gesture language to be employed as a paradigmatic model in the study on the origin of language in general.

A historical clarification is necessary at this stage: Tylor's assessment of the mental faculties of "savages" and "deaf-and-dumb" (as they were commonly called at that time) is unsettling to our modern minds. His classification seems to imply a negative evaluation of the cognitive faculties of "lower races" and "dumb people", who are likened to children and placed at the bottom of a hypothetical evolutionary scale of human development. Sure enough, this was the consensus view among many academics at Tylor's time. Tylor's work on gesture language, nonetheless, had the merit of undermining this conception, as it shed some light on the complexity of sign languages.

Tylor's work on sign language relied on his direct acquaintance with the teaching methods that were applied in some British and German institutions that he personally visited (Tylor 1870: 16). Having observed deaf-mute people in those contexts, he notes the existence of two codes: first, "the real deaf-and dumb language of signs, in which objects and actions are expressed by pantomimic gestures"; secondly, the "deaf-anddumb finger alphabet..." (Tylor 1870: 17). The two systems, he points out, are radically different: the former is the actual deaf-mute native language; the latter is a substitute for alphabetic writing, which in turn reproduces the able-bodied people's spoken language.

Tylor advances a further distinction between "natural signs", i.e. signs that were invented within the deaf-mute community without the intervention of non-hearing-impaired people; and "artificial signs", i.e. those introduced in the community by teachers, who are usually non-hearing-impaired. Tylor stresses the intrinsic vitality of the natural sign language: in particular, he notes how deaf-mute children make up new gestures to communicate with one another while playing, and how they prefer these signs to those proposed by the teachers. Tylor thus significantly quotes Abbé Sicard, who admitted: "Is it for the deaf-and dumb to make them [the signs, ndr] and for me to tell how they are made" (Tylor 1870: 19).

where, whether for good or ill, suggestive pantomime is now reduced to so small a compass in social talk, and even in public oratory" (Tylor 1871: I, 149). 
The main feature of natural gesture language is, as already mentioned, the fully evident connection between object and sign. This does not mean, however, that sign language never shows any feature of arbitrariness; Tylor (1870: 24) quotes as an example a German deaf-mute community in which the adjective "French" was indicated by the gesture for "decapitation", with a clear reference to the French Revolution. In this case, the feature ("those who decapitated the king") that is picked out to identify a class ("French") is entirely arbitrary - though it is true that once grasped, the sign-object connection is also perfectly plain. Matters stand differently for what concerns verbal modes and tenses, grammatical words and terms indicating abstract concepts, such as the verb "to be" or absolute "space" and "time". Tylor emphasises how these have a place in sign language only insofar as they are borrowings from spoken languages, artificially introduced by teachers. However:

These partly artificial systems... are not the real gesture-language [...]. So far as I can learn, few or none of the factitious grammatical signs will bear even the short journey from the schoolroom to the playground, where is no longer any verb "to be", where the abstract conjunctions are unknown, where mere positions, quality, action, may serve to describe substantive and adjective alike. (Tylor 1870: 23)

Tylor's critical target here seems to be the theory of primeval roots proposed by Max Müller in his very fortunate Lectures on the Science of Language (1861). In his Lecture IX: The Theoretical Stage, And The Origin Of Language, the German Sanskritist claimed that comparative philology had been able to demonstrate that complexity may be reduced to a handful of primitive roots. Such roots, therefore, were to be considered the original core from which all existing languages developed. In Müller's view, the British Academy was bogged down by out-dated Eighteenth century philosophical theories, and was happy to continue providing simple materialistic accounts according to which the origin of language was to be envisaged in onomatopoeia (bow-wow theory) or interjections (pooh-pooh theory). Müller's stark criticism was clearly targeted at the theories put forth by two Victorian philologists: firstly, Reverend Frederic Farrar, who, in his Essay on the Origin of Language (1860), theorised that language springs from imitation; secondly, Hensleigh Wedgwood, Darwin's famous cousin and brother-in-law, who, in his essay On Onomatopoeia (1845) and in his Dictionary of English Etimology (1859), developed a similar thesis, 
stressing the connection between this theory, Lyell's Uniformitarianism and Darwin's Biological Evolutionism. ${ }^{4}$ Müller never explicitly mentions either of the two philologists, but his audience was well familiar with their theories. In Müller's view, Farrar's and Wedgwood's hypotheses resulted from the roughest application of evolutionist materialism to biology and cognition: mental faculties had gradually evolved just as much as biological structures, so it was possible, indeed necessary, to individuate intermediary stages. Onomatopoeia - produced by the imitation faculty - and interjection the offspring of emotion -, were thus understood as the first seeds from which articulate language sprung. The latter, therefore, was to be seen as a specific faculty of the rational animal, yet as not essentially separate from its origins, since these were shared with brutes and lower animals. ${ }^{5}$ In contrast with this, Müller argued through a plethora of etymological evidences that the early roots of language were not derived from either interjection or onomatopoeia, but were linked to verbs, that is, abstract concepts. It was clear, therefore, that a mind different from that of brutes had originally produced them.

The 400 or 500 roots which remain as the constituent elements in different families of language are not interjections, nor are they imitations. They are phonetic types produced by a power inherent in human nature. They exist, as Plato would say, by nature; though with Plato we should add that, when we say by nature, we mean by the hand of God. (...) Man, in his primitive and perfect state, was not only endowed, like the brute, with the power of expressing his sensations by interjections, and his perceptions by onomatopoieia. He possessed likewise the faculty of giving more articulate expression to the rational conceptions of his mind. That faculty was not of his own making. It was an instinct, an instinct of the mind as irresistible as any other instinct. So far as language is the production of that instinct, it belongs to the realm of nature. (Müller 1861: 384-5)

To Müller, therefore, primitive language was an instinct. It had emerged in its perfect form directly from the hands of God, and it was only due to a process of degeneration - which Müller explicitly explained in terms of Darwinian evolutionism - that the different tongues had developed out

\footnotetext{
Among the many works on linguistics studies at the time of Darwin, see Knoll (1986), Alter (2007-2008), Gensini $(2011,2014)$. On the theories endorsing the imitative origin of language, see Piattelli (2014) and her article within this collection.

For the sake of historical accuracy, I shall specify that Wedgwood's theory was not continuist as it seems in Müller's interpretation, see Piattelli (2014).
} 
of it. Such a hypothesis satisfied the Victorian polite society as it managed to reconcile Evolutionism with Creationism, which seemed incompatible, without giving in on the one point Anti-Darwinians considered indispensable: the essential difference between men and brutes. This is what grounds the most radical and well known of Müller's positions, expressed in his Lectures: "the one great barrier between the brute and man is Language. Man speaks, and no brute has ever uttered a word. Language is our Rubicon, and no brute will dare to cross it." (Müller 1861: 354-5).

Tylor is well informed on the terms of this debate and his work responds to that of Müller. Having provided an analysis of sign languages, he proceeds to demonstrate the structural kinship between the language of deaf-mute communities and the communication based on gestures of various populations across the world. It is following this approach that Tylor analyses the sophisticated pantomime that Native Americans use for commercial purposes, the actio of Roman orators' and the gestures with which Mediterranean people accompany their speech. Even the English, who are normally sparing in their movements, safeguard a trace of that initial stage in which gestures were the basic elements of communication in a number of codified gestures such as bowing or taking off one's hat. Tylor thus advances a true "kinesic" theory, which envisages expressive gestures as the missing link between animal communication and human language. By virtue of their expressive immediacy, gestures preserve a clear connection to the objects they represent. From a pre-semiotic point of view, moreover, gestures relate to the biology of the beings that produced them: in this sense, Tylor traces the origin of some forms of greeting, such as kissing or rubbing noses, in the pleasurable sensations produced by physical contact (Tylor 1870:45-53). In a way, conventional gestures of civilised populations may be seen as proper "survivals", in the technical sense Tylor attributes to this term:

These are processes, customs, opinions, and so forth, which have been carried on by force of habit into a new state of society different from that in which they had their original home, and they thus remain as proofs and examples of an older condition of culture out of which a newer has been evolved. (Tylor 1870: 15)

Conventional gestures are therefore to be understood as crystallised forms of natural gestures: they emerged from contexts in which their reference and meaning was evident, but they were then transferred into new contexts in which their immediacy had gone lost and the sign was reiterated by convention. 
Let me be absolutely clear on this crucial point, however: Tylor is not theorising here the existence of successive stages in man's linguistic development. He does not envisage a fully gestural stage followed by an oral stage: this would be impossible, in his account, for gestures and spoken words are never truly separate. Even the borderline case of deaf-mute people does not present an instance of "pure" gestural language, for, as we know, even deaf-mute people, when free to express themselves in their "natural" language, emit some more or less elaborate sounds. In fact, it is probably in this kind of phonic emissions, regularly associated with and inextricably bound to gestures, that one must seek the origin of spoken languages.

\section{Expressive Sounds: rehabilitating Interjection and Onomatopoeia}

This is what prompts Tylor's analysis of phono-acoustic communication. In his Primitive Culture (1871), Tylor divides expressive sounds into two categories: sounds that are meaningful by nature and sounds that are meaningful by virtue of the relevant linguistic system. In the first case, matters stand as follows:

These are sounds of interjectional or imitative character, which have their meaning... by being taken up directly from the world of sound into the world of sense. Like pantomimic gestures, they are capable of conveying their meaning by themselves, without reference to the particular language they are used in connection with. (Tylor 1871: 145)

The two faculties that Müller had explicitly rejected when discussing the origin of language thus re-emerge: on the one hand, imitation, which generates onomatopoeia; on the other, emotion, which originates interjection. Tylor, however, frames these two elements in a completely different manner from the way Farrar and Wedgwood had done: in particular, interjection is conceived of as tied to all those features of sound (pitch, emotional tone, speed etc.) that convey the speaker's inner disposition, even independently from his actual communicative intention. In such cases, the quality of the sound emission provides clues for the decodification of emotions and communicative intentions, but also, for instance, on the speaker's frame and other physical qualities. A voice's timbre, for instance, supplies a clear indication of the size of the speaker's vocal trait, and, therefore, also of his body structure. 
Just like natural gestures, expressive sounds are, at least partly, liable to be codified. Consider how, together with their native tongue, children learn to modulate their tone of voice so as to express the emotion that underlie their utterings or give them a particular meaning. In particular, going back to our example of vocal timbre as what gives away the speaker's bodily frame, one might think of children and their attempt to speak with a stern voice when they try to imitate adults. It must be noted here that it is not necessary for uttered sounds to "make sense" in the imitated language. By the end of their language training, children learn to associate emotional tones to meanings in such an immediate manner that the operation seems to them entirely intuitive, not culturally learned. Thus, no neurotypical adult struggles to recognise a genuine laughter from a ridiculising one, or a straightforward assertion from a sarcastic comment.

The sum total of emotional expressions, imitative signs and expressive gestures form the Natural Language, which is a common feature of human kind: "Now joining gesture-actions and gesture-sounds, they will form together what may be called a Natural Language." (Tylor 1881: 122).

A crucial question now ensues, however: if Natural Language is shared by all human beings, does that entail that it is also common to lower humans and animals? Directly faced with the question of continuity, Tylor's linguistic theory touches its most critical point: while on the one hand it seems evident that animals make use of the Natural Language for communication purposes, ${ }^{6}$ yet the author appears somewhat reluctant to embrace continuity tout-court:

That is, a young child can understand what is not proved to have entered into the mind of the cleverest dog, elephant, or ape, that a sound may be used as the sign of a thought or / idea. Thus, while the lower animals share with man the beginnings of the natural language, they hardly get beyond its rudiments, while the human mind easily goes on to higher stages. (Tylor 1881: 122)

The hesitancy derives from the impossibility of establishing with certainty what happens in the animal's mind when it is interpreting the communication sign: how is the human researcher to determine whether animals' responses to certain events (for example, the barking of hunting dogs in presence of a prey) are the products of reasoning or simple reactions to a stimulus?

$6 \quad$ Cf. what follows: "When gestures and cries serve as signals to other creatures, they come near to real signs. The lower animals as well as man do make gestures and cries which act as communications, being perceived by others..." (Tylor 1881: 123). 
Apparently, Tylor writes, animals cannot access the level of reasoning, while men can; thus, in Tylor's account, there is a gap between man and animal.

Tylor's contemporaries were quick to note such a partial subscription to the continuity theory. In reviewing Anthropology, Alfred Russell Wallace was the first to charge Tylor with the following paradox:

In treating of the origin of language Mr. Tylor doubts the sufficiency of the theory that emotional, imitative, and suggestive sounds were the basis on which all languages were founded, though he gives tolerably full illustrations of how roots thus obtained became modified in an infinite variety of ways to serve the growing needs of mankind in expressing their wants or their feelings. (Wallace 1881: 243)

Tylor, however, does not push his inquiry beyond the limit posed by the uncharted territory of animal mind. While he does provide an account of the gestural and para-verbal forms of communication, he does not claim that they constitute the "missing link" between human and animal communication: he thus bypasses the problem, leaving the opposition between continuity and discontinuity theories unsolved. Tylor, in any case, does not seem to mind and the only opinion he expresses on the origin of language is as follows:

Now all this certainly has taken place, but it would be unscientific to accept it as a complete explanation of the origin of language. Besides the emotional and imitative ways, several other devices have here been shown in which man chooses sounds to express thoughts, and who knows what other causes may have helped? All we have a right to say is, that from what is known of man's ways of choosing signs, it is likely that there was always some kind of fitness or connection which led to each particular sound being taken to express a particular thought. This seems to be the most reasonable opinion to be held as to the famous problem of the Origin of Language. (Tylor 1881: 130)

In sum, when it comes to the debate over the continuity between humans and animals, Tylor provides some precious arguments in support of the continuity view, yet he does not fully embrace it. He does, however, subscribe to the Darwinian theory of fitness, which he applies to signs: the primitive connection between sign and meaning rests on a natural basis, which is established in accordance with the rules of fitness. On the one hand, this position is not entirely unlike Müller's theory of degeneration from original roots; on the other, however, it sheds light on the theoretical gap 
that separates Tylor's anthropology from Müller's philological framework. For Müller's language is a monolith: it is something that is either possessed in toto or not at all (see Nicholls 2014). In Tylor's view, instead, language is a "frayed" faculty, as it were: something that may rise by degrees or leaps but is somewhat in connection with other, different kinds of communication that we share with animals. To an extent, this conception associated Tylor to the upholders of the continuity theory. The latter, however, thought that settling the question of the origin of language was of vital importance, as the applicability of Evolutionism to man's cognitive faculties depended on that; Tylor, on the other hand, defined such speculations as "metaphysical" and explicitly expunged them from the domain of his new science. For cultural anthropology deals with "culture", understood as the set of expressions that belong to man as a social being: thus, while language is certainly among its objects, its phylogenesis is not. In other words, the study of the transition from a-linguistic to linguistic beings falls outside the domain of Tylor's newly founded discipline.

In those same years, the question of continuity between systems of communication flowed into the new field of research of animal psychology, which was then in the process of forming as a science. I am referring in particular to those studies that anticipated the issues later explored by zoosemiotics, such as Darwin's Expression of Emotions in Man and Animals (1872) and the works by his pupil George J. Romanes - more specifically, Animal Intelligence (1882) and Mental Evolution in Animals (1883). Such a line of inquiry, however, was not to be particularly successful, due to the overwhelming popularity that behaviourism was soon to obtain in UK and US.

\section{Conclusion: A tent for the King's army}

When a philosopher has a truth in his hands, he is apt to stretch it farther then it will bear. The magic umbrella must spread and spread till it becomes a tent wide enough to shelt the king's army.

(Tylor 1871: 146)

The Victorian debate on the origin of language, which was inextricably entwined with the question of Darwinian Evolutionism, thus saw the opposition of two lines of interpretation: the first, represented by Max Müller, embraced the so-called "Rubicon theory" of language; the second, to which Tylor, among others, belonged, was somewhat frayed at the edges but was also fundamentally continuist, insofar as it envisaged a continuity 
between species and communication systems. In this respect, it is interesting to recall the review Wallace wrote for Anthropology in 1881. Here, the coauthor of the theory of evolution criticised Tylor for not being bold enough in his application of the imitation theory to the origin of language; moreover, Wallace urged Tylor to go back to Farrar's Origin of language.

Tylor's caution, however, makes sense, if one considers that his linguistic studies belonged to a different theoretical framework from that of his predecessors: the new discipline of cultural anthropology was not concerned with the issue of the phylogenesis (or the ontogenesis, for that matter) of language, but only with language as a cultural manifestation of human kind. Thus, Tylor was able to entirely bypass the thorny question posed by Wallace without thereby undermining the validity of his own anthropological work.

On the other hand, it is worth noticing how the Victorian debate itself had ended up in an impasse, getting out of which required a true paradigm shift. The opposition between "Müllerians" and "Darwinians" can in fact be interpreted as an opposition between two radically different manners of understanding language. Müller, following Von Humboldt and Herder, conceived of language as a "divine breath" and as an indivisible unity of thought and word, along the lines of German Romanticism. In contrast with that, upholders of the continuity theory (which predates Darwin but finds new lymph in his evolution theory), basing themselves on the great tradition of British Empiricists, saw language as "one faculty among many". Considering such diametrically opposed assumptions, it is perfectly understandable that such a conception made no sense to the Romantic, philological mind of Müller. The opposition, therefore, is not merely a contrast between two alternative theories: rather, it is an opposition between theoretical frameworks that are immeasurable insofar as they are grounded on different metaphysical assumptions.

Cultural anthropology has thus the following merit, among many others: that of having reframed the terms of debate so as to lead the discussion on language into a new era.

\section{References}

Aarsleff, H. (1967). The Study of Language in England. Princeton: Princeton University Press.

Alter, S. (2007) Darwin and the Linguists: the Coevolution of Mind and Language, Part1. Problematic friends. Studies in History and Philosophy of Biological and Biomedical Sciences, 38: 573-84. 
Alter, S. (2008). Darwin and the Linguists: the Coevolution of Mind and Language, Part 2. The Language-Thought Relationship. Studies in History and Philosophy of Biological and Biomedical Sciences, 39, 38-50.

Bucchi, S., Gensini, S. (eds.) (2014) Darwiniana. Evoluzione e comunicazione. Dai vermi all'intelligenza artificiale. Pisa: ETS.

Darwin, C. R. (1859). On the Origin of Species by Means of Natural Selection, or the Preservation of Favoured Races in the Struggle for Life. London: John Murray.

Darwin, C. R. (1871). The Descent of Man, and Selection in Relation to Sex [2 vols]. London: John Murray.

Gensini, S. (2011). Darwin e il dibattito linguistico coevo. Paradigmi, 24(2), 47-66.

Gensini, S. (2014). Darwin e l'origine del linguaggio: fra storia naturale e teoria. In Bucchi \& Gensini (eds) (2014): 54-76.

Knoll, E. (1986). The Science of Language and the Evolution of Mind: Max Muller's Quarrel with Darwinism. Journal of the History of the Behavioral Sciences, $22,3-22$.

Mocerino, R. (2015). Linguaggio e natura umana: il dibattito sul linguaggio come dispositivo specie-specifico negli studi americani di antropologia (1775-1871) (Unpublished Doctoral Dissertation). Sapienza University, Rome.

Müller, M. (1861). Lectures on the Science of Language. First Series. London: Longman, Green, Longman and Roberts.

Nicholls, A. (2014). A Germanic Reception in England: Friedrich Max Müller's Critique of Darwin's Descent of Man. In T. F. Glick and E. Shaffer (eds.) The Literary and Cultural Reception of Charles Darwin in Europe, vol. 3, 78-100. London and New York: Bloomsbury.

Piattelli, M. (2014). Una fonte di Darwin: Hensleigh Wedgwood e l'origine naturale del linguaggio. In Bucchi \& Gensini (eds) (2014): 77-94.

Piattelli, M. (2016, forthcoming). Hensleigh Wedgwood, Charles Darwin, and the Imitative Origin of Language. In Nobile, L. (ed.) Towards A History of Sound Symbolic Theories [provisional title],. Amsterdam: John Benjamins.

Stocking, G. W. (1968). Race, Culture and Evolution: Essays in the History of Evolution. New York: Free Press.

Stocking, G. W. (1973). From chronology to ethnology: James Cowles Prichard and British anthropology, 1800-1850. In Researches into the Physical History of Man, ed. by George W. Stocking [ $1^{\text {st }}$ ed. 1813], ix-cx. Chicago: University of Chicago Press.

Stocking, G. W. (1987). Victorian Anthropology. New York: Free Press.

Tylor, E. B. (1865). On the Origin of Language. Fortnightly review, (o.s.) 4, 544-559.

Tylor, E. B. (1870). Researches into the Early History of Mankind and the Development of Civilization [ $2^{\text {nd }}$ ed.]. London: John Murray.

Tylor, E. B. (1871). Primitive Culture: Researches into the Development of Mythology, Philosophy, Religion, Language, Art, and Customs [2 vols]. John Murray, London.

Tylor, E.B. (1881). Anthropology: An Introduction to the Study of Man and Civilization. London: Mac Millan. 